\title{
ASPECTOS GENÉTICOS DO TEMPO PARA O FLORESCIMENTO EM VARIANTES NATURAIS DE SOJA ${ }^{1}$
}

\author{
EMÍDIO RIZZO BONATO² e NATAL ANTONIO VELLO³
}

\begin{abstract}
RESUMO - Com o objetivo de melhor entender os mecanismos genéticos do tempo para o florescimento em soja (Glycine max (L.) Merrill), foram estudados os genitores e as gerações $\mathrm{F}_{2}$ de um dialelo com a cultivar Paraná e seus variantes naturais Paranagoiana, SS-1 e Pirapó 78. Os dados foram obtidos em condições de campo com o fotoperíodo variando de 13 horas e 31 minutos, na data de semeadura, ao máximo de 14 horas e 23 minutos, 59 dias após. Não foi constatada a presença de epistasia na determinação do caráter. O principal componente de variação genética foi o aditivo. Os resultados evidenciaram que o retardamento do início do florescimento é determinado por alelos recessivos. Os alelos que condicionaram a precocidade exibiram dominância parcial. As herdabilidades nos sentidos amplo e restrito foram $99,68 \%$ e $89,96 \%$, respectivamente. As informações genéticas sobre o tempo para o florescimento apresentadas, se avaliadas em conjunto com os resultados obtidos por outros pesquisadores, indicam que o tipo de herança depende mais dos genótipos considerados que de uma faixa fotoperiódica específica.
\end{abstract}

Termos para indexação: Glycine max, análise dialélica, componentes genéticos.

GENETIC ASPECTS OF THE TIME TO FLOWERING IN NATURAL VARIANTS OF SOYBEAN

\begin{abstract}
The parents and $\mathrm{F}_{2}$ generations of a diallel cross with soybean (Glycine max (L.) Merrill) cultivar Paraná and its natural variants Paranagoiana, SS-1, and Pirapó 78 were studied with the objective of expanding the available knowledge on the genetic mechanisms of the time to flowering in soybean. Data were obtained under field conditions with photoperiod varying from 13 hours and 31 minutes, at planting date, to a maximum of 14 hours and 23 minutes, 59 days afterwards. No presence of epistasis was found in trait determination. The main component of genetic variation was additive. The results showed that the delay in initial flowering was determined by recessive alleles. The alleles conditioning earliness were partially dominant. Broad and narrow sense heritabilities were $99.68 \%$ and $89.96 \%$, respectively. The genetic information presented on the time to flowering, if evaluated jointly with the results obtained by other investigators, indicated that the type of inheritance is more dependent on the genotypes considered than on a specific photoperiodic band.
\end{abstract}

Index terms: Glycine max, diallel analysis, genetic components.

\section{INTRODUÇ̃̃̃O}

A adaptação de cultivares de soja de hábito de crescimento determinado a diferentes latitudes depende essencialmente do tempo necessário para que iniciem seu florescimento e, conseqüentemente, atinjam sua maturidade. Até o momento, foram descri-

\footnotetext{
${ }^{1}$ Aceito para publicação em 4 de agosto de 1998.

${ }^{2}$ Eng. Agr., Dr., Embrapa-Centro Nacional de Pesquisa de Trigo (CNPT), Caixa Postal 569, CEP 99001-970 Passo Fundo, RS. Bolsista do CNPq. E-mail: bonato@cnpt.embrapa.br

${ }^{3}$ Eng. Agr., Dr., Prof. Titular, Escola Superior de Agricultura "Luiz de Queiroz", USP, Caixa Postal 83, CEP 13400-970 Piracicaba, SP. E-mail: naavello@carpa.ciagri.usp.br
}

tos cinco genes responsáveis pelo controle do tempo para o florescimento e para a maturidade em soja em condições de dias longos, $E_{1} / e_{1}$ e $E_{2} / e_{2}$ por Bernard (1971), $\mathrm{E}_{3} / \mathrm{e}_{3}$ por Buzzell (1971), $\mathrm{E}_{4} / \mathrm{e}_{4}$ por Buzzell \& Voldeng (1980) e $\mathrm{E}_{5} / \mathrm{e}_{5}$ por McBlain \& Bernard (1987). Nas condições de dias longos, os alelos dominantes desses locos são responsáveis pelo ciclo tardio, e os recessivos determinam o ciclo mais precoce. Já nas condições de dias curtos, ocorre o inverso (Kiihl, 1976; Hartwig \& Kiihl, 1979; Tisselli Junior, 1981). Ray et al. (1995) descreveram, em dias curtos, o gene $\mathrm{J} 1 / \mathrm{j} 1$.

Apesar da importância do conhecimento dos mecanismos envolvidos no controle do caráter tem- 
po para o florescimento, poucos estudos têm sido feitos nas condições brasileiras. Toledo \& Kiihl (1982a), estudando o tempo para o florescimento no cruzamento D72-7842 x Santa Maria, evidenciaram que a aditividade foi o principal componente dos efeitos genéticos. Constataram, ainda, que a dominância parcial era no sentido do florescimento mais precoce. Resultados semelhantes foram observados em um dialelo envolvendo cinco genitores (Toledo \& Kiihl, 1982b). As herdabilidades no sentido restrito estimadas nos dois estudos foram de $86,46 \%$, no primeiro, e de $75,23 \%$, no segundo.

O presente trabalho teve por objetivo estudar os mecanismos genéticos envolvidos na determinação do tempo para o florescimento em um dialelo com quatro genitores de soja.

\section{MATERIAL E MÉTODOS}

Foram estudadas plantas individuais de quatro genitores e da geração $F_{2}$ de seis cruzamentos dialélicos formados pela cultivar Paraná e por seus variantes naturais Paranagoiana, SS-1 e Pirapó 78. O estudo foi feito em Londrina, PR, localizada a $23^{\circ} 22^{\prime}$ de latitude sul. O fotoperíodo, da semeadura ao início do florescimento do genitor mais precoce, variou de 13 horas e 31 minutos a 14 horas e 19 minutos. O mais longo foi de 14 horas e 23 minutos, ocorrido 59 dias após a semeadura. As cultivares Paranagoiana e SS-1 são resultantes de mutações naturais ocorridas na cultivar Paraná (OCEPAR, 1988). 'Pirapó 78' é, provavelmente, resultante de cruzamento natural envolvendo o genótipo da cultivar Paraná (Derbyshire et al., 1990).

As sementes $\mathrm{F}_{2}$ foram provenientes da Embrapa-Centro Nacional de Pesquisa de Soja (CNPSo). A semeadura foi feita em 23 de outubro de 1985 em delineamento de blocos ao acaso, com parcelas divididas e cinco repetições. As parcelas foram formadas por seis subparcelas, sendo duas correspondentes aos genitores de um cruzamento em particular e as outras quatro representantes da geração $F_{2}$. Cada subparcela foi constituída por uma fileira de $4 \mathrm{mx} 1 \mathrm{~m}$, contendo dez plantas por metro linear. A emergência ocorreu em 29 de outubro. O número de dias para o início do florescimento (R 1) foi anotado diariamente, em oito plantas de cada genitor e em 60 plantas de cada $\mathrm{F}_{2}$, por repetição; todas as plantas avaliadas estavam em condições normais de competição e foram tomadas ao acaso.

Para manter constante o número de repetições entre os genitores e as respectivas gerações $\mathrm{F}_{2}$, optou-se por fazer a análise a partir dos dados de uma subparcela de cada genitor, tomada ao acaso em cada repetição. A análise da variância foi feita pelo método proposto por Hayman (1954) e adaptado para a geração $F_{2}$ por Jinks (1956). Os componentes e os parâmetros genéticos, estimados pela metodologia proposta por Ferreira (1985), foram:

$\hat{\mathrm{D}}=$ estimativa do componente da variância devido aos efeitos gênicos aditivos;

$\hat{\mathrm{H}}_{1}$ = estimativa do componente da variância devido aos efeitos de dominância dos genes;

$\hat{\mathrm{H}}_{2}$ = estimativa do componente da variância genética dominante corrigida para a distribuição gênica. Indica a assimetria dos efeitos positivos e negativos dos genes; $\hat{\mathrm{F}}=$ estimativa do componente genético da covariância entre os efeitos aditivos e dominantes dos genes e indicativo das freqüências relativas de genes dominantes e recessivos na população dos genitores;

$\hat{\mathrm{E}}=$ estimativa do componente da variância ambiental; $\left(\hat{\mathrm{H}}_{1} / \hat{\mathrm{D}}\right)^{0,5}=$ estimativa do grau médio de dominância; $\left(4 \hat{\mathrm{D}} \hat{H}_{1}\right)^{0,5}+\hat{\mathrm{F}} /\left(4 \hat{\mathrm{D}} \hat{H}_{1}\right)^{0,5}-\hat{\mathrm{F}}=$ estimativa da razão do número de alelos dominantes para alelos recessivos nos genitores;

$\hat{\mathrm{H}}_{2} / 4 \hat{\mathrm{H}}_{1}=$ estimativa das freqüências médias dos alelos de efeitos positivos e negativos nos locos gênicos em que ocorre dominância;

$\left(\hat{\mathrm{D}}-\hat{\mathrm{H}}_{1}\right)=$ diferença entre as estimativas de variâncias dos efeitos aditivos e dos de dominância dos genes;

$r_{(\mathrm{Wr}}+\mathrm{Vr}_{\mathrm{r}, \mathrm{Yr})}=$ estimativa do coeficiente de correlação entre a covariância mais variância da tabela dialélica, com o número médio de dias para o florescimento;

$b=$ estimativa do coeficiente de regressão das covariâncias sobre as variâncias da tabela dialélica;

$\mathrm{h}^{2}{ }_{\mathrm{a}}=$ herdabilidade no sentido amplo;

$\mathrm{h}_{\mathrm{r}}^{2}=$ herdabilidade no sentido restrito

\section{RESULTADOS E DISCUSSÃO}

As análises apresentadas na Tabela 1 mostram a significância, a $1 \%$ de probabilidade, entre as variâncias médias das progênies $\left(\mathrm{V}_{\mathrm{r}}\right)$, entre as covariâncias médias das progênies com os respectivos genitores não recorrentes $\left(\mathrm{W}_{\mathrm{r}}\right)$ e entre as somas $\left(\mathrm{W}_{\mathrm{r}}+\mathrm{V}_{\mathrm{r}}\right)$. Por outro lado, as estimativas de $\left(\mathrm{W}_{\mathrm{r}}-\mathrm{V}_{\mathrm{r}}\right)$ não foram significativas, indicando haver homogeneidade entre as variâncias e as covariâncias e, conseqüentemente, ausência de epistasia no controle do caráter. Logo, a variação não aditiva, reve- 
lada por $\left(\mathrm{W}_{\mathrm{r}}+\mathrm{V}_{\mathrm{r}}\right)$, deve ser creditada aos efeitos de dominância dos genes. Houve, ainda, diferença altamente significativa entre as repetições para $\left(\mathrm{W}_{\mathrm{r}}-\mathrm{V}_{\mathrm{r}}\right)$. A adequação do modelo aditivo-dominante pode ser comprovada pela estimativa do coeficiente de regressão de $\mathrm{W}_{\mathrm{r}}$ sobre $\mathrm{V}_{\mathrm{r}}$, de 0,9524 (Tabela 2), o qual não diferiu de $b=1(p=0,2619)$, mas foi diferente de $b=0(p=0,0009)$.

Os componentes e os parâmetros genéticos estimados para o número de dias para o florescimento estão nas Tabelas 2 e 3 . O valor de $\hat{\mathrm{F}}$, negativo e significativo a 3,09\% de probabilidade, revela que os alelos recessivos foram mais freqüentes que os dominantes no conjunto dos quatro genitores. $\mathrm{O}$ número de alelos recessivos esteve para o de alelos dominantes em proporção aproximada de 1:0,7. Os genitores mais precoces, Paraná e Pirapó 78, apresentaram maior freqüência de alelos dominantes que de recessivos. O inverso ocorreu com os genitores mais tardios, SS-1 e Paranagoiana (Tabela 3).

$\mathrm{O}$ coeficiente de correlação de $\left(\mathrm{W}_{\mathrm{r}}+\mathrm{V}_{\mathrm{r}}\right)$ com o número médio de dias $\left(\mathrm{Y}_{\mathrm{r}}\right)$ foi de 0,9493. Sendo positivo e próximo da unidade, revela que os alelos recessivos foram os responsáveis pelo retardamento do ciclo. O resultado foi obtido em soja que teve o desenvolvimento em ambiente com variação fotoperiódica de 13 horas e 31 minutos a 14 horas e 23 minutos. A informação obtida difere das relata-

TABELA 1. Análises das variâncias das estimativas de variância $\left(V_{r}\right)$ e de covariâncias $\left(W_{r}\right),\left(W_{r}+V_{r}\right)$ e $\left(\mathrm{W}_{\mathrm{r}}-\mathrm{V}_{\mathrm{r}}\right)$ do tempo para o florescimento em um dialelo envolvendo quatro genitores de soja.

\begin{tabular}{lccccc}
\hline \multirow{2}{*}{$\begin{array}{l}\text { Fonte de } \\
\text { variação }\end{array}$} & G.L. & \multicolumn{4}{c}{ Quadrado médio } \\
\cline { 3 - 6 } Linhas & 3 & $2.862,6080^{* *}$ & $2.601,9540^{* *}$ & $10.917,2500^{* *}$ & 11,8879 \\
Repetições & 4 & 61,8919 & 126,4082 & 337,1289 & $39,4833^{* *}$ \\
Resíduo & 12 & 65,1768 & 69,9496 & 264,4922 & 5,7568 \\
\hline
\end{tabular}

** Indicam significância a $1 \%$ de probabilidade.

TABELA 2. Componentes e parâmetros genéticos obtidos pela análise de um dialelo com quatro genitores de soja.

\begin{tabular}{lclc}
\hline Componente & Estimativa \pm erro padrão & Parâmetro & Estimativa \\
\hline$\hat{\mathrm{D}}$ & $159,1012^{* *} \pm 1,2436$ & $\left(\hat{\mathrm{H}}_{1} / \hat{\mathrm{D}}\right)^{0,5}$ & 0,5494 \\
$\hat{\mathrm{H}}_{1}$ & $48,0301 \pm 16,2062$ & $\left(4 \hat{\mathrm{D}}_{1}\right)^{0,5}+\hat{\mathrm{F}} /\left(4 \hat{\mathrm{D}} \hat{\mathrm{H}}_{1}\right)^{0,5} \mathrm{~F}$ & 0,6823 \\
$\hat{\mathrm{H}}_{2}$ & $43,9575 \pm 14,5789$ & $\hat{\mathrm{H}}_{2} / 4 \hat{\mathrm{H}}_{1}$ & 0,2288 \\
$\hat{\mathrm{F}}$ & $-33,0159^{*} \pm 6,2825$ & $\left(\hat{\mathrm{D}}-\hat{\mathrm{H}}_{1}\right)$ & 111,0711 \\
$\hat{\mathrm{E}}$ & $1,7368 \pm 0,5982$ & $\mathrm{r}_{\left(\mathrm{Wr}_{\mathrm{r}}+\mathrm{V}_{\mathrm{r}}, \mathrm{rr}\right)}$ & 0,9493 \\
& & $\mathrm{~b}$ & 0,9524 \\
& & $\mathrm{~h}_{\mathrm{a}}{ }_{\mathrm{a}}$ & 0,9968 \\
& & $\mathrm{~h}_{\mathrm{r}}{ }_{\mathrm{r}}$ & 0,8996 \\
\hline
\end{tabular}

$* \mathrm{e} * *$ Indicam significância a $5 \%$ e $1 \%$ de probabilidade, respectivamente. 
TABELA 3. Concentração de alelos $(\hat{\mathrm{F}})$ que controlam o tempo para o florescimento em quatro genitores de soja.

\begin{tabular}{lc}
\hline Genitores & $\hat{\mathrm{F}}$ \\
\hline SS-1 & $-94,8126$ \\
Paraná & 93,6868 \\
Pirapó 78 & 28,4504 \\
Paranagoiana & $-93,3561$ \\
\hline
\end{tabular}

das por Bernard (1971), por Buzzell (1971), por Buzzell \& Voldeng (1980) e por McBlain \& Bernard (1987), que constataram serem os alelos dominantes os responsáveis pelo controle do ciclo tardio em condições de dias longos. Está, no entanto, de acordo com os dados observados em dias curtos por Kiihl (1976), por Hartwig \& Kiihl (1979) e por Tisselli Junior (1981), com os obtidos por Gilioli (1979) em fotoperíodos de 10 horas e 56 minutos e 13 horas e 21 minutos, no momento da semeadura, e com os apresentados por Ray et al. (1995) e Vargas (1996) em semeaduras feitas em dias com fotoperíodos ligeiramente inferiores e superiores a 14 horas. Os resultados obtidos neste estudo, se interpretados em conjunto com os apresentados pelos pesquisadores acima citados, indicam que o tipo de herança no controle do tempo para o florescimento em soja depende fundamentalmente dos genótipos considerados e não de uma faixa fotoperiódica específica. $\mathrm{O}$ que concorda com a conclusão apresentada por Ray et al. (1995).

Os efeitos dos genes que controlam o tempo para o florescimento foram principalmente aditivos ( $\left.\hat{\mathrm{D}}>\hat{\mathrm{H}}_{1}\right)$. O componente $\hat{\mathrm{D}}$ foi altamente significativo. A significância da estimativa de $\hat{\mathrm{H}}_{1}$ foi detectada a $9,70 \%$, e a de $\hat{\mathrm{H}}_{2}$, a $9,41 \%$ de probabilidade. Os valores de $\hat{\mathrm{H}}_{1}$ e de $\hat{\mathrm{H}}_{2}$ foram muito próximos, revelando a existência de uma simetria entre os genes que aumentam e que reduzem o tempo de florescimento (Tabela 2). A predominância de efeitos aditivos na determinação do tempo para o florescimento foi, também, evidenciada por Toledo \& Kiihl (1982a, 1982b) e por Cecon et al. (1985).

O grau médio de dominância em relação ao tempo para o florescimento foi de 0,5494 , revelando a existência de dominância parcial dos alelos que determinam o ciclo precoce sobre o tardio. A relação entre os alelos recessivos e dominantes (uv) foi de 0,2288 , indicando que entre os genitores estudados existe uma distribuição uniforme desses alelos.

A herdabilidade no sentido amplo foi de 0,9968, e a no sentido restrito foi de 0,8996. Essas estimativas foram semelhantes às observadas por Gilioli (1979) e por Toledo \& Kiihl (1982a, 1982b) e superiores às obtidas por outros pesquisadores, como Destro et al. (1987) e Santos et al. (1987). As altas herdabilidades, tanto no sentido amplo como no restrito, estimadas neste estudo, devem-se à marcante presença da variância gênica, especialmente da aditiva, e ao reduzido efeito do ambiente, conforme pode ser observado na Tabela 2. Essa situação possibilitou constatar que as gerações $\mathrm{F}_{2}$ dos mutantes SS-1 e Paranagoiana com a cultivar original Paraná apresentavam segregação seguindo o padrão monogênico, enquanto o $F_{2}$ entre a cultivar Paraná e o variante Pirapó 78 não mostrava classes fenotípicas bem defenidas.

\section{CONCLUSÕES}

1. O principal componente da variação genética na determinação do tempo para o florescimento é aditivo.

2. O retardamento para o início do florescimento é determinado por alelos recessivos.

3. Os alelos que condicionam o florescimento mais precoce exibem dominância parcial.

4. O tipo de herança no controle do tempo para o florescimento em soja depende mais dos genótipos considerados que de uma faixa fotoperiódica específica.

\section{REFERENCIAS}

BERNARD, R.L. Two major genes of flowering and maturity in soybeans. Crop Science, Madison, v.11, p.242-244, 1971.

BUZZELL, R.I. Inheritance of soybean flowering response to fluorescent-daylength conditions. Canadian Journal of Genetics and Citology, Ottawa, v.13, p.703-707, 1971. 
BUZZELL, R.I.; VOLDENG, H.D. Inheritance of sensibility to long daylength. Soybean Genetics Newsletter, Ames, v.7, p.26-29, 1980.

CECON, P.R.; SEDIYAMA, C.S.; REGAZZI, A.J.; SEDIYAMA, T. Análise das gerações $\mathrm{F}_{2}$ e $\mathrm{F}_{3}$, para estimar variâncias aditivas, de dominância e de ambiente, em um sistema fatorial de cruzamento de soja. Revista Ceres, Viçosa, v.32, p.470-487, 1985.

DERBYSHIRE, E.; CARVALHO, M.T.V.; BONATO, E.R. Comparison of natural variants of the soybean cultivar Paraná by isoenzyme analysis. Brazilian Journal of Genetics, Ribeirão Preto, v.13, p.83-87, 1990.

DESTRO, D.; SEDIYAMA, T.; SILVA, J.C.; SEDIYAMA, C.S.; THIÉBAUT, J.T.L. Estimativas de herdabilidade de alguns caracteres em dois cruzamentos de soja. Pesquisa Agropecuária Brasileira, Brasília, v.22, n.3, p.291-304, mar. 1987.

FERREIRA, P.E. On Jinks-Hayman's analysis of half dialleles. Brazilian Journal of Genetics, Ribeirão Preto, v.8, p.149-155, 1985.

GILIOLI, J.L. Herança do número de dias para a floração e maturação em quatro mutantes naturais em soja (Glycine max (L.) Merrill). Viçosa: UFV, 1979. 42p. Tese de Mestrado.

HARTWIG, E.E.; KIIHL, R.A.S. Identification and utilization of a delayed flowering character in soybeans for short-day conditions. Field Crops Reseach, Amsterdam, v.2, p.45-51, 1979.

HAYMAN, B.I. The theory and analysis of diallel crosses. Genetics, Princeton, v.39, p.789-809, 1954.

JINKS, J.L. The $\mathrm{F}_{2}$ and backcross generations from a set of diallel crosses. Heredity, London, v.10, p.1-30, 1956.

KIIHL, R.A. de S. Inheritance studies of two characters in soybean (Glycine max (L.) Merrill): I. Resistance to soybean mosaic virus; II. Late flowering under short-day conditions. Starkville: Mississippi State University, 1976. 56p. Ph.D. Thesis.

McBLAIN, B.A.; BERNARD, R.L. A new gene affecting the time of flowering and maturity in soybeans. Journal of Heredity, Washington, DC, v.78, p.160-162, 1987.

OCEPAR (Cascavel, PR). Recomendações para a cultura da soja no Paraná, 1988/89. Cascavel: OCEPAR/Londrina: Embrapa-CNPSo, 1988. 94p. (OCEPAR. Boletim técnico, 23; Embrapa-CNPSo, Documentos, 34).

RAY, D.J.; HINSON, K.H.; MANKONO, J.E.B.; MALO, M.F. Genetic control of a long-juvenile trait in soybean. Crop Science, Madison, v.35, p.1001-1006, 1995.

SANTOS, A.L.M.; SEDIYAMA, C.S.; MORAES, C.F.; SEDIYAMA, T. Seleções praticadas no verão e no inverno nas gerações $\mathrm{F}_{2}$ e $\mathrm{F}_{3}$ de um cruzamento de soja. Revista Ceres, Viçosa, v.34 p.33-41, 1987.

TISSELLI JUNIOR, O. Inheritance study of the longjuvenile characteristic in soybeans under longand short-day conditions. Starkville: Mississippi State University, 1981. 77p. Ph.D. Thesis.

TOLEDO, J.F.F.; KIIHL, R.A. de S. Análise do modelo genético envolvido no controle de dias para o florescimento em soja. Pesquisa Agropecuária Brasileira, Brasília, v.17, n.4, p.623-631, abr. 1982a.

TOLEDO, J.F.F.; KIIHL, R.A. de S. Método de análise dialélica do modelo genético em controle das características dias para floração e número de folhas trifolioladas em soja. Pesquisa Agropecuária Brasileira, Brasília, v.17, n.5, p.745-755, maio 1982b.

VARGAS, A.T. Estudo genético em mutantes naturais de florescimento tardio provenientes de cultivares de soja (Glycine max (L.) Merrill). Londrina: UEL, 1996. 120p. Tese de Mestrado. 